\title{
IRRADIACIÓN CULTURAL FRENTE A RUPTURA DIPLOMÁTICA. EL MESIANISMO FRANCÉS ANTE EL CIERRE DE LA FRONTERA ESPAÑOLA, 1946-1948.
}

\author{
ISABELLE CABROLIER-LOSTANLEN
}

Université de Provence - UMR - Telemme

RESUMEN: En este trabajo se estudia la postura alternativa asumida por los responsables de la red cultural francesa en España durante el cierre de frontera entre 1946 y 1948, en defensa del mantenimiento del marco de intercambio entre ambos países. Después de la segunda guerra mundial, Francia necesita reafirmarse en su imagen de defensora universal de los valores democráticos. En este contexto, la oposición al régimen franquista constituye un marco propicio para la recuperación de su papel mesiánico. Sin embargo, a partir de la misma concepción de la "misión de Francia» con relación a la España de Franco, surgen dos posturas divergentes. Desde París, una opinión pública fuertemente movilizada reclama para Francia el liderazgo de la condena internacional y pide el boicot al régimen. En cambio, desde los centros educativos y culturales franceses en España se intenta demostrar que el único papel que Francia está en condiciones de desempeñar para contribuir al restablecimiento de la democracia en España, es precisamente el mantenimiento de los contactos culturales e intelectuales, a efectos de poder constituir para los demócratas españoles una posibilidad de apertura de horizontes.

Palabras Clave: Cierre de la frontera franco-española. Centros culturales franceses en España. Mesianismo francés.

ABSTRACT: This work is a study of the option chosen by the men in charge of the French cultural network in Spain, during the closing of the Franco-Spanish frontier, in the years 1946-1948. Their intention was to maintain the cultural exchanges policy between both countries. After World War II, France needed to reaffirm her image as a defender of democratic values, this was the context for the French opposition to the Franco regime. It was also seen as an opportunity to recover her messianic role. However, this conception of "France's mission» in relation to Franco's Spain, in fact, generated two opposing positions. In Paris, a strongly held opinion argued 
that France had to be the leader of international disapproval, and demanded a boycott of the regime. On the other hand, the people who ran the French art and Education centres in Spain tried to prove that the only valid position France could consider was to maintain cultural and intellectual contacts, in order to represent an opportunity for Spanish democrats to broaden their horizons.

KEY WORDS: Franco-Spanish frontier closing. French Art Centres in Spain. French messianism.

La fundación de las primeras escuelas francesas en España comenzó a mediados del siglo XIX. Por aquella época, algunas órdenes religiosas abandonaron Francia y abrieron centros escolares en territorio español ${ }^{1}$. Posteriormente, a raíz de la instalación de colonias francesas en torno a los polos de actividad económica e industrial (puertos, minas, ferrocarriles, fábricas de gas y de electricidad), las Sociedades de Beneficencia y de Socorros Mutuos, y también algunas empresas, fundaron escuelas laicas para cubrir las necesidades educativas de los hijos de expatriados ${ }^{2}$.

Aquella fase de «creaciones espontáneas» finalizó después de la Primera Guerra Mundial. Para entonces, la colonia francesa que financiaba las escuelas se encontraban en pleno declive. Por otro lado, el Ministerio de Asuntos Exteriores estaba dando un nuevo impulso a los organismos encargados de la acción cultural exterior. Así, el modesto Bureau des Ecoles et des Oeuvres Françaises à l'étranger, fundado en 1909³ , dejó lugar en 1920 al Service des Oeuvres Françaises à l'étranger $(\mathrm{SOFE})^{4}$, dotado de una estructura mucho más desarrollada. En la península ibérica, a partir de 1919, el Estado tomaba el relevo de la colonia a través del Office de l'Enseignement français en Espagne $e^{5}$, cuya tarea consistía en distribuir las subvenciones oficiales destinadas al mantenimiento de la red escolar francesa.

${ }^{1}$ Jean-Marc Delaunay, «L'Espagne, un champ ouvert. Rivalités et illusions culturelles en péninsule ibérique (XIXe-XXe)», Relations Internationales, n. 50 (été 1987), p. 216.

${ }^{2}$ En los últimos decenios del siglo XIX, la colonia francesa fundó un Instituto francés en Madrid y escuelas primarias en Barcelona. Las creaciones continuaron después de 1900 en San Sebastián y Sevilla mientras que las sociedades francesas o belgas abrieron escuelas en Huelva, Peñarroya y Torrelavega. Rapport de M. Paul Guinard, attaché culturel auprès de l'Ambassade de France, novembre 1954. Archives du Ministère des Affaires étrangères-France (AMAE-F), Relations Culturelles, Enseignement 1948-1961, vol. 225.

3 Histoires de diplomatie culturelle des origines à 1995, Paris, Ministère des Affaires Etrangères-La Documentation Française, 1995, p. 36.

${ }_{4}^{4}$ Antoine MARES, «Puissance et présence culturelle de la France. Le Service des Oeuvres Françaises à l'étranger dans les années 30», Relations Internationales, n. 33 (printemps 1983), pp. 6580; Gilles MatThieu, Une ambition sud-américaine. Politique culturelle de la France (1914-1940) Paris, L'Harmattan, 1991; pp. 65-71, y Antonio NiÑO, «1898-1936: orígenes y despliegue de la política cultural hacia América Latina», en España, Francia y América Latina. Políticas culturales, propagandas y relaciones internacionales, Siglo XX. Paris, L'Harmattan, 2001, chap. I. pp. 24-163.

5 A partir de 1932 se llamó Comité des Écoles franco-espagnoles. 
En ese lapso de tiempo, para los países industrializados la guerra de 19141918 había constituido una suerte de catalizador. Los gobiernos habían tomado conciencia de la necesidad de que el Estado contara con una capacidad de control sobre la difusión de su imagen tanto en el interior como en el exterior de sus fronteras. En efecto, durante el conflicto, los contendientes habían tenido que enfrentarse en un nuevo campo de batalla: el de la opinión pública nacional y europea. Como consecuencia de ello, los organismos de propaganda entraron a formar parte del arsenal de los países en guerra. Una vez restablecida la paz, la propaganda como tal desapareció, pero se procedió a la adecuación de sus instrumentos al nuevo contexto internacional para transformarlos en servicios de acción cultural. Dichos instrumentos se dirigían ahora a un público diferente: las élites de países terceros cuya captación debía facilitar la realización de objetivos políticos, económicos y estratégicos.

Sin embargo, la acción cultural en el extranjero no se limitaba a perseguir objetivos exteriores. Mediante la difusión del idioma y de las producciones culturales, se trataba de exportar «la imagen de marca» elaborada por las clases dirigentes ${ }^{6}$ como base de la identidad y de la cohesión nacionales. En un país como Francia, esa interacción de apuestas interiores y exteriores, en el marco de la acción cultural, revistió un carácter especial. En efecto, desde la III República, la identidad nacional se forjó en torno a la representación de Francia como país mensajero de los valores democráticos, con una misión a cumplir: la emancipación intelectual del género humano.

Si los antecedentes de la incorporación del factor cultural al arsenal diplomático se remontan a aquellos años, lo cierto es que su verdadera eclosión tuvo lugar después de la Segunda Guerra mundial7. En Francia, después de cuatro años de guerra y de ocupación alemana, la situación se presentaba como «un balance de ruinas». Las pérdidas humanas y las destrucciones materiales eran considerables: «la tercera parte de la riqueza francesa ha sido aniquilada» ${ }^{8}$. Además, los años del gobierno de Vichy habían quebrado la unidad nacional, y los partidarios de la Resistencia y de la colaboración estaban ajustando cuentas? ${ }^{9}$ La hora de la depuración y de las condenas a muerte había llegado. Para emprender el camino de «la grandeur» ${ }^{10}$, el Gobierno Provisional del General de Gaulle no sólo debía estimular la economía nacional, sino también pasar la página del período de la ocupación para poder restablecer el orden público y restaurar la imagen de «Patria de los Derechos Humanos» que la colaboración con la Ale-

${ }^{6}$ Pierre MiLzA, «Culture et relations internationales», Relations Internationales, n. 50 (été 1987), p. 365.

7 Histoires de diplomatie culturelle..., pp. 76-77.

${ }^{8}$ Charles de Gaulle, Mémoires de guerre, Le salut 1944-1946, Paris, 1959, T.III, pp. 272-274.

9 Jean TOUCHARD, Le gaullisme 1940-1969, Paris, 1978, pp. 74-76 y Robert O. PAXTON, La France de Vichy. 1940-1944, Paris, 1997, pp. 385-438.

10 "La route de la grandeur est libre. Mais la France, pour s'y engager, dans quel état a-t-elle été mise?», Charles de Gaulle, Mémoires de guerre..., p. 272. 
mania nazi había dañado seriamente ${ }^{11}$. En ese contexto de restauración del prestigio nacional, la acción cultural exterior surgía como instrumento particularmente útil, como se apreciaba en diversos escenarios geográficos ${ }^{12}$. Fue entonces cuando Louis Joxe ${ }^{13}$ tomó las riendas de la Direction Générale des Relations Culturelles (DGRC), en 1946.

En tal sentido, la España de Franco ofrecía un terreno propicio para el ejercicio del mesianismo francés. En efecto, no sólo la red de centros escolares y culturales era densa, sino que el carácter dictatorial del régimen español brindaba a un país sumergido en plena depuración una gran oportunidad para reafirmar su compromiso en la defensa de los valores democráticos. Francia encabezó la condena internacional del régimen bajo la presión de una opinión pública fuertemente movilizada, que pedía la adopción del boicot como medida de apoyo a la resistencia frente al dictador. Mantener intercambios con España era interpretado por esa opinión pública como una forma de «collaboration» con Franco.

Durante dos años, a partir del 1 de marzo de 1946, la frontera francoespañola permaneció cerrada y la situación de los funcionarios franceses encargados de la red cultural se tornó muy delicada ¿Qué línea de conducta iban a adoptar los responsables políticos, cuando precisamente desde la opinión pública francesa se valoraban las relaciones con España desde el prisma de la ocupación alemana y, por lo tanto, se percibían como una forma de «collaboration»? ¿De qué modo los numerosos centros escolares e Institutos franceses podían conciliar la oposición radical de Francia hacia el régimen franquista con sus actividades en España?

En las páginas que siguen trataremos de sopesar el contexto y las condiciones materiales y morales en que se desenvolvió la red cultural francesa en aquella coyuntura crítica, cómo logró mantener su actividad en un entorno adverso hasta la reapertura de la frontera en febrero de 1948.

11 «...l'ordre intérieur et la position extérieure de la France exigeaient que la capitulation, la rupture des alliances, la collaboration délibérée avec l'ennemi fussent jugées sans tarder dans la personne des dirigeants qui s'en étaient rendus responsables. Sans cela, au nom de quoi, châtier les exécutants? Comment, au nom de quoi, prétendre pour la France à un rang de grande puissance belligérante et victorieuse?». Charles de GAULLE, Mémoires de guerre..., p. 129.

12 Sobre la estrategia utilizada por Francia para recuperar entre las repúblicas latinoamericanas su imagen como país abanderado y faro de la libertad, vid. Lorenzo DeLGaDo GómezESCALONILLA, «La cultura como vanguardia de la política exterior: Francia, España y América Latina en la postguerra mundial», en España, Francia y América Latina. Políticas culturales, propagandas y relaciones internacionales. Siglo XX, Paris, L'Harmattan, 2001, pp. 307-401.

${ }^{13}$ Louis Joxe (1901-1991): Secretario de Estado del Ministerio de Asuntos Exteriores en los años treinta, fue destituído por el gobierno de Vichy. En 1943, De Gaulle lo nombró Secretario General del Comité Français de Libération Nationale (CFLN). En 1946 volvió al Quai d'Orsay, en la DGRC. Luego, Louis Joxe desempeñó varios cargos oficiales en calidad de embajador o ministro. 


\section{SiTUACIÓN MATERIAL Y LEGAL DE LOS CENTROS CULTURALES FRANCESES.}

La creación de la DGRC incitó a los universitarios franceses destinados en España a emprender una reflexión plasmada en la redacción de un informe elaborado por Paul Guinard, Director del Instituto Francés de Madrid y Agregado Cultural de la Embajada de Francia ${ }^{14}$. Además de ofrecer una visión de conjunto, el documento proponía una serie de orientaciones para una red cultural que debía, tras ocho años de honda agitación, adaptarse a un contexto radicalmente nuevo.

En el momento del cierre de la frontera, la estructura cultural francesa en España abarcaba un conjunto de medios de acción: dos grandes Liceos en Madrid y Barcelona más sendos Institutos franceses en cada una de estas ciudades; una delegación del Instituto en Valencia, Bilbao y Zaragoza; 16 escuelas franco-españolas o cursos subvencionados; 16 bibliotecas y un lector en la Universidad de Salamanca. En varias escuelas se organizaban clases nocturnas. En Madrid contaban con 900 alumnos, en Barcelona con 110015. Habría que esperar al año 1951 para que la Alliance Française, que antes de la guerra civil disponía de varios comités establecidos en el país, retomase sus actividades.

Comparada con otras potencias, Francia poseía en 1945 un número superior de centros en España, pero ya no era el único país que apostaba por la acción cultural exterior como medio para consolidar su influencia. Si se consideraba a Italia como un rival menor, Alemania en cambio aparecía como un competidor muy serio dado que, aunque se encontraba despojada de sus organismos oficiales, la cultura y el prestigio de los científicos alemanes seguían gozando de un fuerte poder de atracción entre los españoles. Pero sobre todo eran los ingleses, y en menor medida los norteamericanos, quienes desplegaban un esfuerzo que los propios franceses consideraban metódico e inteligente, y cuyo impacto comenzaba a dejarse sentir.

Con motivo de la inauguración del Instituto Británico, el Agregado Cultural Walter Starkie declaraba que su país «estaba siguiendo el feliz ejemplo de las escuelas francesas». Los recién llegados se instalaban en edificios modernos, en buen estado y con una dotación suficiente de material. En Sevilla, el Instituto Británico abría en un amplio y hermoso palacio, lo que motivaba la preocupación del cónsul francés por la presencia de un edificio tan bien restaurado y equipado situado solamente "a dos tiros de fusil de la escuela francesa» ${ }^{16}$. Desde Valencia, donde los ingleses acababan también de inaugurar un Instituto, el cónsul escribía con amargura:

14 «Les oeuvres françaises en Espagne. Perspectives de travail et problèmes d'avenir», 16-I1945. AMAE-F, Relations culturelles, Enseignement 1945-1947, vol. 51.

15 DGRC: «Les œuvres françaises en Espagne», 20-XII-1946. AMAE-F, Europe 1944/1949, Espagne, vol. 97.

${ }_{16}$ M. O. D’Alexandry, Consul de France à Séville à la DGRC, 3-II-1946. AMAE-F, Relations Culturelles, Enseignement 1945-1947, vol. 51. 
«J'hésite à comparer la situation actuelle du nouvel Institut Britannique à celui du Collège français dont le budget est alimenté par une subvention du Département fixée en dernier lieu à 30.000 francs et dont le personnel enseignant de nationalité française n'est, malgré un effectif de 600 élèves, constitué que par ses deux directeurs auxquels aucun traitement n'a d'ailleurs été versé depuis le $1^{\text {er }}$ janvier $1945 » 17$.

Por consiguiente, la antigüedad de la presencia cultural francesa en España en relación a los demás países era susceptible de constituir hasta cierto punto una suerte de desventaja. Con el aumento constante de la demanda y la apertura de nuevas secciones, los centros culturales y escolares se habían quedado pequeños además de vetustos. Algunos habían sufrido daños durante la guerra civil, y las obras de rehabilitación tardaban en realizarse. En Barcelona, uno de los dos grupos escolares situado en un barrio al sur de la ciudad (calle Sepúlveda) fue totalmente destruido por un bombardeo en 1937 y, a pesar de las reiteradas peticiones de Jacques Coiffard, cónsul en la ciudad, nunca fue reconstruido. El Liceo de Madrid albergó varios miles de «asilados» de la Embajada de Francia y sufrió daños importantes. El pésimo estado del edificio ponía en peligro la seguridad de los alumnos: en 1947 el deterioro se extendía a la mayoría de las puertas y ventanas, los revestimientos de las fachadas estaban desmoronándose y los fragmentos de material caían al patio de recreo desde el quinto piso $^{18}$. Además, para salir de la situación de ilegalidad en la cual se encontraba, el Liceo debía construir nuevas aulas para la sección española, y de esta forma adecuarse a los reglamentos vigentes.

Después de la ocupación de su local, el Instituto Francés de Madrid había sido objeto de reparaciones, pero se postergaban los proyectos que contemplaban la necesidad de ampliarlo o de transferirlo a otro sitio. El centro «literalmente no puede respirar en un edificio demasiado pequeño y mal diseñado»19, escribía Guinard en su informe. Por su parte, la Casa de Velázquez, alto símbolo de la presencia francesa en España, se encontraba a finales de 1947 todavía en estado ruinoso $^{20}$. Aún cuando bajo la dirección de los funcionarios mandados por Vichy los centros franceses no habían sufrido apenas saqueos de su material (tal como ocurrió en Barcelona, donde cientos de libros desaparecieron de la biblio-

${ }_{17}$ M. Gouge Consul de France à Valence à Mr. le Délégué en Espagne du Gouvernement Provisoire de la République Française, 9-VI-1945. AMAE-F, Relations culturelles, Enseignement 1945-1947 vol. 51.

${ }_{18}$ Note sur le Lycée Français de Madrid, décembre 1947. AMAE-F, Relations Culturelles, Enseignement 1945-1947, vol. 54.

19 Rapport de M. Paul Guinard, novembre 1954, doc. cit.

20 El 3-XII-1947 Bernard Hardion se dirigió al Ministerio de Asuntos Exteriores para pedir que se tomase una decisión a propósito de las ruinas de la Casa de Velázquez. Estaban obstaculizando el proyecto urbanístico de las vías de acceso a Madrid y la contemplación de las ruinas recordaba «de forma lamentable los más tristes episodios de la guerra civil». AMAE-F, Relations Culturelles, Enseignement 1945-1947, vol. 55. 
teca del Instituto durante «la disidencia») ${ }^{21}$, los centros franceses carecían de libros y de revistas, especialmente científicas. Asimismo, acusaban un retraso notable en comparación con los anglosajones respecto a la utilización de las nuevas herramientas de acción cultural, como la divulgación científica, el cine, los discos, o las ediciones económicas de libros, herramientas éstas que en España entraban «poco a poco en las costumbres» ${ }^{22}$. Un antiguo profesor del Liceo Francés de Madrid denunciaba en 1945 el reducido espacio de las salas del Instituto, la incomodidad de una sala de conferencias excesivamente pequeña y dotada de un material escaso y arcaico, a la par que pedía presupuestos adecuados para afrontar la competencia con medios modernos.

«Il est à mon avis regrettable de négliger cet aspect de la propagande française à l'étranger, les directeurs devraient disposer de crédits suffisants pour compléter ou rajeunir leur matériel suivant les besoins et pour recevoir les étrangers dans les meilleures conditions» ${ }^{23}$.

Pero la época no se prestaba al incremento de recursos económicos para la acción cultural en España. Las restricciones presupuestarias habían comenzado: alcanzarían entre un 15 y un $35 \%$ hasta los años cincuenta. Las demandas económicas necesarias para la reconstrucción y la modernización de Francia llevaban a plantearse «un objetivo a medio plazo: la auto-financiación económica de los centros controlados» 24 .

Por otra parte, para los centros franceses la adaptación no se reducía a una mera cuestión de locales o de dotación de material. Después de la guerra civil, las autoridades españolas parecían querer poner fin al amplio margen de maniobra del cual disponían los centros extranjeros. Los responsables franceses habían notado ese cambio:

«Même après le retour de la paix, nous ne retrouverons jamais les facilités de jadis. N'oublions pas que par rapport à la période qui précéda la guerre civile, deux facteurs nouveaux sont apparus, et subsisteront. D'abord le contrôle de l'enseignement privé par l'État espagnol et la réglementation des établissements étrangers sont devenus très stricts» 25 .

A finales de agosto de 1939, el embajador francés en Madrid, Philippe Pétain, preocupado al ver al Colegio Alemán dispuesto a funcionar a partir del 1

${ }^{21}$ Paul Guinard, «Note sur les activités des Instituts et des Lycées d'Espagne», novembre 1944. AMAE-F, Relations Culturelles 1945-1947, Enseignement, Espagne, vol. 55.

${ }_{22}$ Note du Ministère des Affaires étrangères: «Relations culturelles avec l'Espagne et le Portugal», 10-X-1946. AMAE-F, Europe 1944-1949, Espagne, vol. 97.

${ }^{23}$ AMAE-F, Relations Culturelles, Enseignement 1945-1947, vol. 51.

${ }^{24}$ Anne Dulphy, La politique de la France à l'égard de l'Espagne de 1945 à 1955. Entre idéologie et réalisme, Paris, Ministère des Affaires étrangères, 2002. p. 314.

25 «Les oeuvres françaises en Espagne...», 16-I-1945, doc.cit., p. 4. 
de octubre, solicitaba la autorización para reabrir los centros franceses. Se le concedió dos semanas después, pero a título provisional, limitada al curso 1939-1940 y bajo la condición de que el gobierno francés aceptase la reciprocidad $^{26}$. Más tarde, un intercambio de notas entre el Conde Renom de la Baume, nuevo Embajador francés, y el general Juan Beigbeder, Ministro de Asuntos Exteriores español, fechadas en 21 y 23 de septiembre de 1940, imponía a los centros franceses en España pasar del régimen de «libertad prácticamente total» a la adopción «de un régimen de control y de autorización previa». Además, en virtud de los acuerdos firmados, la legitimidad de la presencia cultural francesa descansaba en la aceptación desde París del principio de reciprocidad:

«1. Le gouvernement français envisage avec faveur toute mesure aidant sur la base de la réciprocité à une meilleure connaissance en France de la langue et de la civilisation espagnoles et en Espagne de la langue et de la civilisation françaises...

2. Le gouvernement français admet que les deux gouvernements puissent entretenir l'un chez l'autre, sur la base de la réciprocité, le même nombre d'écoles dans la France métropolitaine et l'Espagne métropolitaine d'une part et dans l'Afrique espagnole et l'Afrique française d'autre part...»27.

Según Paul Guinard, ese documento colocaba a la red cultural francesa en una posición jurídica «extremadamente débil», ya que a pesar del acuerdo ultimado, el Estado español distaba mucho de beneficiarse de las mismas facilidades para abrir escuelas en Francia ${ }^{28}$. Por lo tanto, la desigualdad hacía pesar sobre los Institutos culturales y los centros escolares «la espada de Damocles de la reciprocidad $\gg^{29}$. Aunque retrospectivamente se puede cuestionar la voluntad real de las autoridades españolas de llevar a la práctica las amenazas de cierre, el riesgo potencial era latente en un contexto bilateral crispado.

${ }^{26}$ El 14-X-1939, el Ministerio de Asuntos Exteriores transmitió a la Embajada de Francia en Madrid: «...se ha concedido la oportuna autorización para que los Establecimientos de enseñanza franceses (...) puedan funcionar durante el presente curso escolar, en la inteligencia de que dicha autorización tiene carácter meramente provisional y se halla subordinada a la reciprocidad de trato que en Francia se conceda a los Establecimientos de Enseñanza españoles en ella establecidos». Archivo del Ministerio de Asuntos Exteriores-España (AMAE-E), R 8586/20.

27 «3. Les écoles françaises d'Espagne ou d'Afrique espagnole feront dans leur enseignement une place à la langue, à l'bistoire et à la géographie espagnoles, les écoles espagnoles de France et d'Afrique française feront dans leur enseignement une place à la langue, à l'bistoire et à la géographie françaises [...]. 4. "Le gouvernement français serait obligé au gouvernement espagnol de vouloir bien comme il en a manifesté l'intention, accorder aux écoles d'Espagne une autorisation définitive...». La Delegación de Madrid comunicó al Quai d'Orsay el contenido de la nota del 21-IX-1940. AMAE-F, Relations Culturelles, Enseignement 1945-1947, vol. 52.

${ }^{28}$ Lorenzo Delgado GómeZ-ESCAlONilla y Antonio NiÑO, «Emigración, enseñanza y nacionalidad en las relaciones hispano-francesas», Historia Contemporánea, num. 10 (1993), pp. 51101, y Lorenzo Delgado GómeZ-EsCALONILLA, «La enseñanza de los emigrantes. Entre la defensa de la identidad española y la política de asimilación francesa», Hispania, num. 211, vol. LXII/2 (2002), pp. 521-560.

29 Note de Paul Guinard, 15-X-1947. AMAE-F, Relations Culturelles, Enseignement 19451947 , vol. 55 . 
En virtud de las nuevas disposiciones, los centros franceses de ahora en adelante deberían someterse a nuevas reglas. En las escuelas primarias, todos los alumnos españoles recibirían diariamente una educación religiosa impartida según las normas establecidas para las escuelas oficiales. Las escuelas francesas adoptarían la separación de niñas y niños. En cada nivel, todos los alumnos asistirían a seis horas semanales dedicadas al estudio del idioma, de la geografía y de la historia de España. Esas clases correrían a cargo de profesores titulares del sistema público español.

Esta intervención de las autoridades españolas en el funcionamiento de los centros franceses se acompañaba de su progresiva hispanización. El declive de la colonia francesa había provocado el cierre de las escuelas de Córdoba, Málaga, La Coruña, Tarragona, y Alicante. En dos ciudades cercanas a la frontera ${ }^{30}$, Barcelona y San Sebastián permanecían las únicas escuelas verdaderamente francesas, donde la enseñanza era idéntica a la que se impartía en Perpiñán y $\mathrm{Pau}^{31}$. En otras partes, como en Valencia o Sevilla (que acogían a más de 500 alumnos), o en Salamanca y Huelva (donde los efectivos eran más reducidos), la dirección era francesa, pero en los niveles de primaria y de secundaria se daba una enseñanza casi española, y las familias oponían incluso resistencia a la enseñanza del idioma francés por considerarla una sobrecarga horaria inútil.

«...insuffisance du personnel, manque d'homogénéité des groupes. On arrive péniblement à avoir chaque année quelques bons candidats aux examens de langue française organisés par le Comité des Écoles; et si tous les élèves quittent l'École avec quelques notions de français, bien peu le parlent convenablement. Et cela, il faut le répéter, malgré le dévouement des maittres et le mérite réel de certains d'entre eux»32.

Con 1.800 alumnos en 1945, el Liceo de Madrid era uno de los principales centros escolares franceses en el extranjero. Si en primaria las clases se impartían en francés, los alumnos se orientaban luego hacia la sección secundaria española. En ella, los esfuerzos para estimular el estudio del francés se juzgaban decepcionantes.

En cambio, el Liceo de Barcelona, cuyos efectivos eran más reducidos en Madrid, se asemejaba más a un liceo francés. La sección española se encontraba

30 Después de 1945 son tres. En efecto, a petición del Inspector General Masbou, una pareja de maestros franceses llega a Bilbao en 1946 para tomar la dirección de la escuela e impulsar en ella la enseñanza francesa. En los años succesivos, como en Barcelona y San Sebastián, la escuela de Bilbao impartirá una enseñanza primaria exclusivamente francesa. Rapport de Monsieur Masbou, Inspecteur Général, sur l'École Française de Bilbao, avril 1947. AMAE-F, Relations Culturelles, Enseignement 1945-1947, vol. 52.

Vid también dos informes de Paul Guinard: L'attaché culturel en Espagne à Monsieur le Ministre Délégué du G.P.R.F. , 11-VII-1946. AMAE-F, Relations Culturelles, Enseignement 1945-1947, vol. 54. y Rapport de Monsieur Paul Guinard, novembre 1954, doc. cit.

31 «Les oeuvres françaises en Espagne...», 16-I-1945, doc.cit. p.28.

32 «Les oeuvres françaises en Espagne...», 16-I-1945 doc.cit., p. 29. 
en pleno desarrollo y mantenía en común con la sección francesa gran parte de la enseñanza impartida. Esta situación se debía a la presencia de una colonia francesa más numerosa que en Madrid, pero sobre todo las «simpatías contestatarias» de la población aseguraban a la enseñanza francesa una mejor recepción entre el público catalán.

En suma, la densidad de la red de centros escolares franceses ya no tenía relación con los escenarios demográficos, políticos y económicos que rodearon su creación. Es más, el Estado francés disminuía progresivamente su aportación financiera, de ahí el dilema que planteaba Paul Guinard:

«Que devons-nous faire? Faut-il jeter le manche après la cognée? Faut-il considérer que ces Écoles vouées à mourir ou à s'abâtardir, représentent une charge hors de proportion avec leur rendement et un luxe que la France ne peut plus s'offrir?»33.

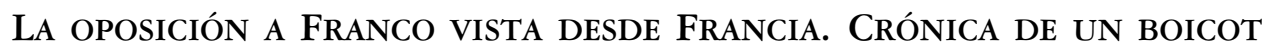 ANUNCIADO}

Ahora bien, con el tenso clima bilateral, las dificultades materiales se hacían más acuciantes, y la amenaza de cierre de los centros por el incumplimiento del acuerdo de reciprocidad se hacía más aguda. Los funcionarios franceses residentes en España se encontraban en una posición complicada. En efecto, estaban a contracorriente de una opinión pública francesa favorable al boicot, pero a la vez, a los ojos de las autoridades españolas representaban un país hostil al régimen.

En Francia, la oposición al franquismo era mucho más activa en la medida que el país había vivido de cerca los acontecimientos de la guerra civil, y había experimentado un sentimiento de culpabilidad por no haber apoyado la Segunda República española. Se manifestaba la voluntad de tener una segunda oportunidad situándose esta vez del lado bueno ${ }^{34}$. En enero de 1945, la Asamblea Constituyente votó una moción que solicitaba al gobierno la ruptura con Franco. La actitud de firmeza frente al dictador no se limitaba a un objetivo exterior, sino que constituía también un elemento de cohesión del «matrimonio de conveniencia» ${ }^{35}$ que unía el MRP ${ }^{36}$, la $\mathrm{SFIO}^{37}$ y el PC en el seno del gobierno

\footnotetext{
33 Ibidem, p. 30.

${ }_{34}^{4}$ Paola BRUNDU, «L'Espagne franquiste et la politique étrangère de la France au lendemain de la seconde guerre mondiale» Relations Internationales, n50 (été 1987), pp. 165-166.

35 Jean-Paul COINTET, «Gouvernement Provisoire de la République française» en Dictionnaire historique de la vie politique française au XX ème siècle, (sous la direction de Jean-François SIRINELLI), Paris, P.U.F. 2004, p. 542.

36 Mouvement Républicain Populaire: fundado en 1944, reunió a demócratas cristianos ligados a la Resistencia como el Ministro de Asuntos Exteriores, G. Bidault. El MRP desapareció en 1967.

37 Section Française de l'Internationale Ouvrière, partido fundado en 1905. Desapareció en 1969 con la creación del Parti Socialiste.
} 
tripartito, formado el 23 de enero de 1946 después que De Gaulle anunciara su salida del ejecutivo.

Sin embargo, el hecho de considerar el boicot al régimen franquista como una oportunidad para asumir un liderazgo en un tema de política internacional, y reservar para Francia el papel de potencia intermedia entre los dos bloques $^{38}$, colocaba a la red cultural en una posición totalmente inédita. Si desde la creación del SOFE, en 1920, se concebía la presencia cultural como una herramienta de apoyo al despliegue económico y político nacional, en la inmediata postguerra una parte de la clase política y una opinión pública movilizada operaban una distinción entre la imagen de Francia (en su calidad de «Patria de los Derechos Humanos») y sus posiciones políticas y económicas en la península. Ignorando intereses culturales y económicos considerables, ${ }^{39}$ la movilización antifranquista exigía que se invirtieran los términos: Francia no recobraría su prestigio ni contribuiría al restablecimiento de la democracia en España mediante una mayor presencia. Al contrario, para restaurar su imagen de "país faro de la democracia», para ayudar a la oposición y pasar la página de la historia reciente, tenía que renunciar a cualquier tipo de intercambio con el régimen de Franco.

La llegada masiva de refugiados en 1939, el enrolamiento de muchos de ellos en los maquis junto a patriotas franceses, había ligado la Resistencia a los republicanos españoles. Franco, que había llegado al poder con la ayuda de los países del Eje, era su último enemigo común.

En sus Mémoires de guerre, el General de Gaulle cuenta que cuando viajó a la región del suroeste francés en septiembre de1944, los españoles estaban saliendo de la clandestinidad "con el proyecto de entrar armados en su país», "una división española se formaba en la región con el objetivo claramente anunciado de caminar bacia Barcelona». De Gaulle abandonó Toulouse haciendo una promesa muy vaga a los compañeros de combate españoles:

«Je fis connaître aux chefs espagnols que le gouvernement français n'oublierait pas les services qu'eux-mêmes et leurs hommes avaient rendus dans nos maquis, mais que l'accès de la frontière des Pyrénées leur était interdit»40.

El sentimiento de solidaridad que unía la Resistencia francesa a los republicanos españoles otorgó a la cuestión española un giro apasionado, que alcanzó su paroxismo en febrero de 1946 con la ejecución de Cristino García, un militante comunista y antiguo miembro de una de las redes de la Resistencia en la

38 Pedro Antonio MARTINEZ LILLO: Las relaciones bispano-francesas en el marco del aislamiento internacional del régimen franquista (1945-1950) Tesis Doctoral, Universidad Autónoma de Madrid, 1993, pp.70-71.

39 Las inversiones francesas en España representaban el $60 \%$ del total de las realizadas por este país en el extranjero. Paola BRUNDU, art.cit., p.168.

40 Charles De Gaulle, Mémoires de guerre (Le Salut) 1944-1946, op. cit. pp. 18-20. 
Ardèche ${ }^{41}$. La noticia de la ejecución de un hombre que había luchado junto a la Resistencia francesa en contra de los alemanes provocó una intensa emoción y aceleró la decisión de cerrar la frontera ${ }^{42}$. A partir del 1 de marzo, se suspendió el correo postal y se interrumpió el transporte de mercancías y de pasajeros.

Si en Francia la condena del régimen español era casi general, en cambio, la decisión de cerrar la frontera distaba mucho de ser unánime. En algunos sectores se expresaron protestas contra una medida ineficaz además de perjudicial para los intereses económicos franceses ${ }^{43}$. Según informaban la Embajada de Francia en Madrid y el Cónsul de Barcelona, una caída del régimen era improbable ${ }^{44}$. No obstante, era el precio que había que pagar para asegurar una especie de catarsis y mantener el orden interior. Georges Bidault ${ }^{45}$ confesó, años después, que tan sólo una decisión radical había podido «impedir que se desencadenaran las pasiones».

En Francia la oposición antifranquista y las campañas del Partido Comunista y de la CGT ${ }^{46}$ tendían a crear una amalgama que acabó confundiendo y rechazando a la vez a Franco y al pueblo español. De ese modo, el diputado comunista André Marty protestaba ante el Ministerio de Asuntos Exteriores contra la llegada a la Cité Universitaire de 46 estudiantes españoles becados, y solicitaba que los fondos empleados para esos jóvenes instruidos bajo la ideología nazi fueran utilizados en ayudar a estudiantes franceses en situación precaria ${ }^{47}$.

La representación de una España poblada únicamente por partidarios del régimen, la idea de que la única actitud admisible era el boicot, ponían en tela de juicio el comportamiento de los responsables de la acción cultural francesa. Así, en febrero de 1947 Louis Joxe remitía a la Embajada de Francia un artículo publicado unos días antes en Ce Soir, el diario dirigido por Louis Aragon. El periódico francés se hacía eco de una supuesta información recogida en $L a$ Prensa en la cual se aludía a Pierre Deffontaines y André Dravet, directores, respectivamente, del Instituto y del Liceo Francés de Barcelona:

${ }^{41}$ Anne DulPhy, op. cit., pp.135-142. Acerca de la evolución del exilio español en Francia vid. Geneviève DREYFUS-ARMAND, L'exil des républicains espagnols en France. De la guerre civile à la mort de Franco, Paris, Albin Michel, 1999

42 Aline ANGOUSTURES, «L'opinion publique française et l'Espagne 1945-1975», Revue d'histoire moderne et contemporaine, t. XXXVII (1990), pp. 672-686.

43 Sobre las pérdidas económicas de Francia a causa del cierre de la frontera vid. Anne DULPHY, op. cit. pp. 142-157.

${ }_{44}$ Jean- Marc Delaunay: Des palais en Espagne. L'École des Hautes Études Hispaniques et la Casa de Velázquez au coeur des relations franco-espagnoles du XX ème siècle (1898-1979), Madrid, Bibliothèque de la Casa de Velázquez, pp.382-386.

45 Georges Bidault (1899-1983): miembro de la Resistencia, sustituyó a Jean Moulin como presidente del Comité National de la Résistance y luego fue uno de los dirigentes del MRP. De 1944 a 1954, Bidault fue ministro de varios gobiernos, entre ellos de Asuntos Exteriores (19441948).

46 Confédération Générale du Travail, sindicato cercano al Partido Comunista.

47 AMAE-F, Relations Culturelles, Enseignement 1945-1947, vol. 52. 
«Les directeurs de l'Institut Français exaltent l'œuvre de Franco en inaugurant le collège. Pierre Deffontaines et André Dravet, directeurs, ont exalté l'œuvre de justice et de paix de Franco. Dans la conjoncture actuelle, une telle attitude est encourageante» 48 .

Louis Joxe pidió aclaraciones. El Cónsul en Barcelona negó rotundamente la veracidad de la información publicada por Ce Soir y añadió, además, que en la prensa no se encontró la fuente impresa citada ${ }^{49}$. Ese tipo de incidentes era revelador de la situación. En Mémoires de guerre, el General de Gaulle describe una prensa comunista con numerosas publicaciones: los dos grandes periódicos parisinos L'Humanité y Ce Soir, los 70 semanarios y «las cincuenta hojas publicadas fuera de París pretendían sacar a la luz en todos los lugares el fascismo y sus sabotajes y apoyaban todas las denuncias» ${ }^{50}$.

$\mathrm{Al}$ rendir cuentas del trabajo que efectuaban en España, los responsables de la acción cultural buscaban demostrar que su presencia en la península no constituía una forma de collaboration como sugería o afirmaba la amalgama establecida entre la Resistencia francesa y el boicot al régimen franquista. Por el contrario, los centros culturales y escolares aportaban un apoyo moral e intelectual a los demócratas españoles cuya existencia Francia parecía ignorar. Proponían entonces otra lectura de la «misión de Francia»: exportar el espíritu de la Resistencia francesa y, por extensión, apoyar la resistencia intelectual manteniendo los intercambios con España.

\section{RECUPERACIÓN DEL PRESTIGIO NACIONAL: DIFUSIÓN DEL ESPÍRITU DE LA RESISTENCIA Y DE LA RECONSTRUCCIÓN FRANCESA}

El régimen de Vichy y la política de collaboration con la Alemania nazi habían dañado seriamente la imagen de «Patria de los Derechos Humanos» reivindicada por Francia, y provocado hondas secuelas en la sociedad. Para restaurar el crédito internacional y la cohesión interior era necesario marcar de forma tajante la ruptura con el gobierno de Pétain y destacar el papel desempeñado por una Resistencia unida alrededor de la figura del General de Gaulle

De cara a la proyección exterior, la red cultural ofrecía un canal de difusión eficaz de la campaña de rehabilitación de la imagen nacional. A este respecto, el caso de la misión universitaria francesa en España constituye un ejemplo ilustrativo de cómo, al igual que el resto de la sociedad francesa, las posturas individuales de los funcionarios expatriados distaron de ser tan lineales como $a$ posteriori fueron presentadas en las recapitulaciones oficiales.

${ }^{48}$ Louis Joxe (DGRC), 18-II-1947. AMAE-F, Relations Culturelles, Enseignement 19451947 , vol. 52.

49 Telegrama de Bercegol. Transmite la respuesta de Coiffard, 7-III-1947. AMAE-F, Relations Culturelles, Enseignement, vol. 52.

50 Charles De Gaulle, op.cit., p. 134. 
En el transcurso de los años de postguerra, marcados por la condena del régimen de Vichy y la depuración ${ }^{51}$, en varias ocasiones los funcionarios franceses hicieron hincapié en su adhesión al gobierno de Argel. En una carta dirigida al SOFE, los profesores del Liceo de Madrid recordaban que su compromiso había servido de sostén para la causa gaullista en España y que siempre se habían negado a «colaborar» con los emisarios de Vichy.

«Nous sommes fiers de pouvoir dire aujourd'hui que parmi les fonctionnaires résidant dans une Espagne hostile et germanisée nous avons été les premiers à nous faire l'écho de la voix du Général de Gaulle et à offrir sans aucune réserve à une époque où il n'était pas possible qu'il y eut en Espagne un représentant du Comité de Libération Nationale, notre collaboration aux Missions de Londres puis d'Alger» ${ }^{2}$.

Durante esos años de ostracismo, en un afán de pasar página al régimen de la collaboration, los centros culturales franceses difundieron la obra y los valores de la Resistencia. A este respecto, en un informe relativo al Instituto Francés de Barcelona, Pierre Vilar consideraba como tarea urgente contrarrestar la propaganda franquista sobre el papel que desempeñó la Resistencia francesa durante la ocupación alemana. Requería para la biblioteca del Instituto «los buenos libros acerca del movimiento patriótico de 1940 à 1945 a propósito del cual, por lo menos en España, la información corriente arroja dudas sistemáticas»s3.

A través de la red de bibliotecas ${ }^{54}$, el Instituto Francés se esforzó por dar la mayor difusión posible al papel desempeñado por las fuerzas de la France Libre en la liberación del territorio nacional. El Bulletin de la Bibliothèque de l'Institut Français d'Espagnes5, que incluía en cada número de la lista de las publicaciones recién llegadas a los Institutos de Madrid y Barcelona, informaba sobre la posi-

${ }^{51} \mathrm{La}$ lectura de los informes acerca de los 2000 condenados a muerte por delitos de Colaboración, inspiró este comentario al General de Gaulle: «Rien au monde ne m’a paru plus triste que l'étalage des meurtres, des tortures, des délations, des appels à la trabison qui venaient ainsi sous mes yeux». Charles de GaUlLE, op. cit., p. 127.

52 Jacques Cherprenet au Directeur du SOFE, 6-XII-1944. AMAE-F, Relations Culturelles, Enseignement 1945-1947, vol. 54. El 3 de junio de 1943 se creó el CFLN en Argel. El llamado Gobierno de Argel constituyó la autoridad de la Francia Libre y estuvo encabezado por De Gaulle y el General Giraud. Al cabo de unos meses, De Gaulle consiguió apartar a Giraud del mando

53 Pierre Vilar, Professeur à l'Institut Français de Barcelone, pour le Directeur Général des Relations Culturelles, 5-X-1946. AMAE-F, Relations Culturelles, Enseignement 1945-1947, vol. 51.

${ }_{54}$ Aparte de Madrid y Barcelona, las bibliotecas francesas en España se encontraban en las delegaciones del Instituto de Valencia, Zaragoza, Bilbao y la Maison de France de San Sebastián, las agencias consulares (Sevilla, Valladolid, Las Palmas, Palma de Mallorca), en las Universidades de Granada y de Santiago de Compostela (a finales de 1946, la biblioteca de Salamanca estaba aún en vías de instalación). Bulletin des Bibliothèques de l'Institut Français en Espagne, num. 11 (octubre 1946), p. 2.

55 Las modificaciones del título son indicativas de la evolución de la publicación. En octubre de 1946 se convirtió en Bulletin des Bibliothèques de l'Institut Français en Espagne. En 1950 el título se hizo más conciso: Bulletin de l'Institut Français en Espagne (Bulletin). 
bilidad de enviar libros a cualquier persona, independientemente de su lugar de residencia y de si es o no miembro del Instituto ${ }^{56}$. El número de enero de 1947 , titulado «Témoignages», daba la tónica:

«De la défaite inconcevable et accablante à une victoire chèrement payée, mais dignement méritée par le sursaut de la Résistance, le chemin a été rude»57.

Se ponían a disposición de los lectores nuevos libros sobre la derrota, los campos de concentración, la Ocupación y la Resistencia que completaban el fondo de lecturas ya existente relativo a la France Libre. En el número de octubre de1946, el Bulletin incorporaba la lista de las revistas que llegaban al Instituto, disculpándose por no tener los medios para ofrecer a los lectores más publicaciones $^{58}$. La biblioteca proponía revistas nacidas en la clandestinidad como Poésie 41 de Pierre Seghers en la cual Louis Aragon había publicado en 1941 un poema en homenaje a Saint-Pol Roux, poeta asesinado por soldados alemanes. En su obra, Aragon ligaba la suerte del poeta francés con la de Lorca y Machado59.

Entre las revistas asociadas a la Resistencia, el Instituto Francés proponía L'Arche fundada por André Gide en febrero de 1944 con la participación de Albert Camus, para «agrupar las fuerzas intelectuales y morales de la Francia libre 0 que lucha por serlo» ${ }^{60}$, y otras publicaciones como Confluences y Fontaine. Además, era posible consultar dos revistas importantes, les Temps Modernes dirigida por Jean Paul Sartre y Esprit de Emmanuel Mounier, publicaciones que familiarizaban a los lectores con los grandes debates de la época.

En el número 2 (noviembre de 1945), el Bulletin contenía la lista de los libros recién registrados en la biblioteca. En literatura francesa, de los quince títulos anunciados, ocho son obras de autores miembros de la Resistencia. Entre ellos, Jacques Debû-Bridel, Elsa Triolet y François Mauriac publicaban su obra en la editorial Éditions de Minuit bajo el seudónimo que llevaban en la clandestinidad ${ }^{61}$. Durante los meses siguientes, el fondo de la biblioteca del Instituto Francés segui-

56 «Ajoutons que les spécialistes qui ne trouveraient pas sur place un livre utile à leurs travaux, pourront toujours le demander à Madrid ou à Barcelone. Ils le recevront, même sans être lecteurs régulièrement inscrits, pourvu qu'ils s'engagent à en assurer le retour par poste recommandée dans un délai de 15 jours». Bulletin, ibidem, p. 2.

57 Bulletin, num. 14 (enero de 1947), p. 1.

58 Lista de publicaciones que llegan de forma regular, en Bulletin, num. 11 (octubre de 1946):

Publicaciones bibliográficas y antológicas: 4 .

Revistas literarias y de cultura general: 23.

Ciencias religiosas, históricas y sociales: 26.

Ciencias y técnicas: 19 .

Bellas-Artes, artes aplicadas, moda :18.

Semanarios ilustrados de actualidad: 7 .

59 Michel WinOCK, Le siècle des intellectuels, Paris, 1999, p. 462.

60 Ibidem, p. 488

${ }^{61}$ Jacques Debû-Bridel es Argonne, Elsa Triolet publicó bajo el seudónimo Daniel L. Bajo el nombre Forez se ocultaba François Mauriac. 
rá enriqueciéndose de libros escritos por antiguos resistentes entre los cuales figuraban algunos comunistas. Textos de De Gaulle, Vercors, Lucie Aubrac, Edith Thomas, Albert Camus, Emmanuel Mounier, Pierre Emmanuel, Ramuz, Paul Eluard, Louis Aragon y Romain Rolland estaban al alcance del público español. En mayo de 1947, Marcelin Defourneaux dedicaba una conferencia a Marc Bloch, mientras que el Instituto Francés de Barcelona optaba por exponer la obra de personalidades como Paul Eluard, Pierre Emmanuel y Louis Aragon.

Tanto la obra del propio Jean-Paul Sartre, como los ensayos dedicados a su pensamiento, recibían la más amplia difusión. En el marco de dos conferencias sobre el existencialismo dictadas en el Instituto de Barcelona se presentaba, en febrero de 1947, una lectura de la obra teatral Les Mouches. La reseña de la obra publicada en el número 15 del Bulletin concluía que «cada hombre es libre, cada bombre debe inventar, solo, su propio camino». Mientras tanto, en Madrid, una lectura de Antigone de Jean Anouilh, trataba también del tema de la libertad y de la Resistencia. La reseña de la obra finalizaba con estas palabras:

«Ajoutons enfin que la pièce, qui date de 1942, appartient en quelque manière à la littérature d'occupation, et qu'on y trouve, sinon des allusions caractérisées, au moins un reflet, un écho assourdi, mais bien reconnaissable, des préoccupations de l'époque» 62.

Por otra parte, los Institutos Franceses van a esforzarse por contrarrestar la propaganda franquista en otro terreno: el de la reconstrucción y puesta en marcha del Estado francés. La exposición de libros organizada por el Instituto Francés de Madrid a finales de 1946 había llamado la atención y cosechado un verdadero éxito entre un público «asombrado por la abundancia de la producción francesa y por la calidad de los libros». El representante francés, Bernard Hardion, explicaba que los españoles tendían a representarse Francia en un completo estado de anarquía material y moral, dominada por una dictadura intelectual de extrema izquierda, puesto que así era cómo cierta prensa nacional francófoba solía describir al país ${ }^{63}$. Pierre Vilar había subrayado el papel de información general y objetiva que el centro cultural debía desempeñar, no sólo en el aspecto de la producción literaria y artística francesa sino también en el área social y económica,

«afin de combattre la quotidienne propagande anti-française de la presse. Même nos meilleurs amis hésitent à croire à notre redressement; il faut leur fournir une documentation» ${ }^{64}$.

En marzo de 1947, el Instituto de Madrid organizó una Exposición documental sobre el tema «Reconstrucción de Francia». A partir de fotos, mapas y gráfi-

62 Bulletin, num. 15 (février 1947), pp.11-13.

${ }_{63}$ Bernard Hardion transmite al Quai d'Orsay una carta del Señor. Hugues asesor comercial de la Delegación, 22-XI-1946. AMAE-F, Relations Culturelles, Enseignement 1945-1947, vol. 51.

${ }^{64}$ Pierre Vilar pour le Directeur Général des Relations Culturelles, 5-X-1946, doc.cit. 
cos, el público español tomaba conciencia de la amplitud de las destrucciones, del esfuerzo realizado «y de los resultados obtenidos ya en todas las áreas. Comunicaciones, puertos y construcciones maritimas, producción industrial de todo tipo» ${ }^{65}$. Una serie de tres conferencias pronunciadas por Marcelin Defourneaux y la proyección de tres películas acababan ilustrando el tema. Al mes siguiente, se presentaba la misma exposición en el Instituto de Barcelona acompañada de una conferencia de Pierre Vilar, probable instigador del proyecto. Después de la intervención de Vilar se proyectaron tres películas: Les ruines vous parlent, En 49 jours seulement (construcción de un viaducto), Renflouement. En su número del mes de marzo, en la «Chronique de l'Institut», el Bulletin justificaba la elección del tema.

«L'Institut a voulu présenter, au cours du mois de mars, un Tableau de la Reconstruction de la France: utile mise au point sur une question d'actualité qui ne semble pas toujours être appréciée à la simple lumière des faits» ${ }^{66}$.

Con recursos limitados y la ayuda de los «amigos del Instituto» de Madrid y de Barcelona, los dos centros culturales debían tratar de articular un contrapeso a la propaganda franquista que se empleaba en retratar una Francia decadente en estado de caos. A la inversa, los españoles no se sentían mejor tratados por la prensa francesa. Las autoridades incluso elaboraron una lista de las «injurias francesas contra España», que contabilizaba las numerosas declaraciones públicas en contra del régimen y demostraciones de apoyo acordadas al gobierno Giral. Además, los dirigentes españoles tenían la impresión de que el estado francés no hacía nada para proteger los edificios oficiales contra la acción de los exiliados (consulados, escuelas, edificios de la Avenida Marceau) ${ }^{67}$.

En este contexto de hostilidad recíproca, los centros culturales se esforzaban por encarnar islotes de paz donde hacer posibles los intercambios francoespañoles. Mientras que franceses y españoles se insultaban a través de sus respectivas prensas, entre las paredes del Instituto Francés de Madrid reinaba un clima sereno. Con el cierre de la frontera, se acudía a los recursos humanos locales: músicos españoles actuaban tocando piezas de compositores franceses, instituciones oficiales como el Museo de América, la Biblioteca Nacional, la Real Academia Española y también numerosos coleccionistas prestaban documentos y objetos en el marco de exposiciones dedicadas a Goya, Cervantes o Paul Valéry. Para la exposición titulada «Imágenes napoleónicas», presentada en Madrid a finales del año 1946, el Museo de reproducciones artísticas aceptaba ejecutar una máscara mortuoria de Napoleón a partir del original, y numerosos particulares prestaron su colaboración.

65 Bulletin, num. 16 (mars 1947), p. 13.

66 Ibidem.

67 «Injurias francesas contra España. Campaña antiespañola. Año 1946». AMAE-E, R $3373 / 12$. 
«Malgré l'impossibilité de faire venir des documents de France, un grand nombre de pièces intéressantes avaient pu être réunies, grâce à l'obligeance de collectionneurs madrilènes» 68 .

La lectura del Bulletin durante este período pone de manifiesto que entre un sector de la sociedad española y el Instituto Francés se estableció una cierta colaboración logística. En marzo de 1948, tras la reapertura de la frontera, se organizó una exposición titulada «Gide, Romains y los escritores de la N.R.F» con la colaboración de las Éditions Gallimard. El Bulletin subrayaba el concurso de:

«plusieurs amis madrilènes particulièrement de D. Juan Guerrero Ruiz, D. Felipe Jiménez Sandoval et de Santiago Magariños, qui nous ont une fois de plus permis de puiser dans leurs collections, l'Institut a pu montrer un ensemble suffisamment suggestif de livres d'éditions originales, d'ouvrages critiques et de livres» ${ }^{69}$.

Aparte de recursos materiales, los españoles brindaron asimismo recursos humanos: prestigiosos conferenciantes tomaron la palabra en los centros franceses. En Madrid, Paul Guinard que era historiador del arte, recibía a Francisco Javier Sánchez, director-adjunto del Museo del Prado, a Enrique Lafuente Ferrari, profesor en la Escuela Superior de Bellas Artes, o también a José Camón Aznar de la Universidad de Madrid. En el ámbito literario, el Instituto Francés de Madrid acogía a Ramón Gómez de la Serna y a Gerardo Diego. El de Barcelona abrió sus puertas a numerosos artistas «particularmente orientados» hacia Francia (Manolo Huguet, Clara, Pablo Roig y Rogent), entre los cuales se encontraba Joan Miró quien vivía "completamente retraído en Barcelona» y cuyos únicos contactos giraban alrededor del Instituto Francés. A propósito de esa relación exclusiva de Miró, Pierre Deffontaines escribía a Philippe Rebeyrol, un antiguo profesor:

«J'ai vu longuement Miró qui est de plus en plus un ami. Il est question que nous allions ensemble à Majorque aux vacances de Noël, ce serait magnifique» ${ }^{70}$.

Por otra parte, según Jacques Coiffard, Barcelona era la ciudad más francófila y el arte francés tenía en la capital catalana un eco especial. Las exposiciones cosechaban un éxito fácil en una región que siempre prefirió mirar hacia París, para dar la espalda a Madrid más francamente. Además, la proximidad de Francia había llevado a muchos trabajadores a buscar empleo al otro lado de los Pirineos, "así la lengua francesa se halla muy difundida y es hablada más o menos correctamente por la mayoría de la gente, incluso entre gente bumilde» ${ }^{71}$.

68 Bulletin, num. 13 (diciembre 1946), p. 30.

${ }^{69}$ Bulletin, num. 25 (avril 1948), p. 17.

70 Pierre Deffontaines à Philippe Rebeyrol, 16-XI-1945. AMAE-F, Relations Culturelles, Enseignement 1945-1947, vol. 55.

${ }^{71}$ Pierre Deffontaines: «Note pour le futur Institut Français de Barcelone», 15-I-1945. AMAE-F, Relations Culturelles, Enseignement 1945-1947, vol. 55. 
Finalmente, en la voluntad de destacar la fluidez de los intercambios entre Francia y España, no se evocaba nunca el cierre de la frontera. En forma esporádica se aludía a ciertas «dificultades» para justificar, sin más precisiones, la falta de material. Habrá que esperar a la reapertura para que aparezca la palabra "frontera» asociada esta vez a un contexto favorable. Por contra, con motivo de los homenajes a Goya, Falla y Cervantes, frecuentemente se emplearon las palabras amigo, amor a Francia o a España. José Francés, secretario perpetuo de la Academia de Bellas Artes de San Fernando, acabó como sigue su conferencia en el Instituto Francés de Madrid en 1946:

«Ainsi Falla va revivre parmi nous. La chaleur passionnée de son art va nous unir dans une émotion commune, comme longtemps encore Espagnols et Français, par delà les conjonctures passagères, seront unis dans les zones supérieures de l'art pour écouter le message universel dont était porteur son génie» ${ }^{72}$.

Durante un discurso emitido por la Radio de Madrid, Jean Babelon, conservador del Gabinete de las Medallas de la Biblioteca Nacional, que había venido a Madrid para participar en los trabajos de «la Asamblea cervantina de la lengua española», celebraba él también la amistad entre los dos países y expresaba su admiración por la cultura española:

«C'est pour moi un vrai plaisir que d'apporter ici, en mon nom personnel et en celui des nombreux amis que l'Espagne a en France, le tribut de gratitude que tous les peuples cultivés doivent à la patrie de Cervantès»73.

\section{LA PRESENCIA CULTURAL, VÍA ALTERNATIVA PARA AMPARAR A LA OPOSICIÓN ANTIFRANQUISTA}

Los responsables de la acción cultural en España no limitaron al público español su papel de mediación y de contrainformación. Se esforzaron también por exportar hacia París una imagen menos monolítica de España de la que, según parece, predominaba en Francia. En distintas cartas dirigidas al Ministerio de Asuntos Exteriores, Jacques Coiffard describía una Cataluña tan francófila como opuesta al Caudillo, y descalifica la asociación simplista «que consiste en tratar a España en bloque como si fuera un país de apestados». El cónsul en Barcelona lamentaba tal repudio indiscriminado por parte de representantes de la cultura francesa, ya que al final dicha actitud privaba sobre todo a los demócratas españoles de los contactos necesarios con el exterior.

«... j’ai l'impression, que je souhaite fausse, que bon nombre de ceux qui seraient qualifiés pour représenter ici la pensée française, reculent devant l'idée de

72 Bulletin, num. 13 (diciembre1946), p. 7.

${ }_{73}$ Bulletin, num. 20 (octubre 1947), p. 22. 
venir parler devant un auditoire fascisant. Il faut tout de suite le rassurer. Le public qui fréquente notre Institut n'est pas de ce genre et il a soif d'entendre et de voir des auteurs qu'il vénère et oú sa propre pensée s’inspire» ${ }^{74}$.

Por su parte, Bernard Hardion desmentía a una prensa francesa «más apasionada que informada», que daba a entender que «el franquismo corrompió, esterilizó hasta el pensamiento». Durante su estancia en Madrid, Raymond Lantier, Conservador jefe del Museo de las Antigüedades, constató la presencia en el país de «una élite liberal que, en el interior del propio régimen actual, preserva convicciones liberales y quiere reanudar relaciones fluidas con los medios científicos franceses» 75 .

El Instituto de Barcelona dedicaba una atención particular a las conferencias sobre temas científicos, e intentaba recuperar posiciones en un terreno ocupado por los ingleses y los norteamericanos. La organización de clases públicas, de conferencias y ponencias sobre la investigación francesa favorecieron los contactos entre el Instituto Francés y los medios científicos españoles. En ese contexto, Marie-Louise Josien, doctora en ciencias y encargada por Paul Guinard de la enseñanza científica del Instituto Francés, era invitada por un grupo de científicos madrileños a exponer el tema de la «Investigación francesa de 1940 a 1945». En enero de 1946, el famoso químico Miguel Catalán pronunció dos conferencias en el Instituto Francés de Barcelona. Desde el final de la Guerra Civil, el científico había sido privado de su cátedra en la Universidad de Madrid, y la entrada en el CSIC, organismo creado tras la llegada al poder de Franco, le estaba vedada ${ }^{76}$.

En un informe sobre las actividades del Instituto, Pierre Deffontaines describía una Universidad de Barcelona sin ninguna proyección, «depurada» de todos los elementos catalanistas y republicanos,

«Dans ma spécialité, géographie, le titulaire n’a aucune connaissance de la géographie moderne et s'occupe de la géographie de l'antiquité grecque. D'ailleurs il n'y a pas véritablement d'étudiants et la seule petite équipe de géographes se réunit à l'Institut Français oú je m'occupe de la direction de trois thèses sur la Catalogne»77.

Salvador Llobet y Joan Vila Valentí, discípulos de Pierre Deffontaines, rindieron un homenaje a su antiguo maestro en 1980 en la Revista de Geografía de la Universidad de Barcelona. Con este motivo, los dos geógrafos españoles re-

\footnotetext{
${ }^{74}$ Jacques Coiffard à Georges Bidault, 3-XII-1945. AMAE-F, Relations Culturelles, Enseignement 1945-1947, vol. 51.

${ }_{75}$ Bernard Hardion à Georges Bidault, 30-XI-1945. AMAE-F, Europe 1944/1949, Espagne, vol. 97.

${ }^{76}$ José Manuel SANCHez Ron, Cincel, martillo y piedra (Historia de la ciencia en España siglos XIX y XX), Madrid, Taurus, 1999, pp. 319-327.

77 Pierre Deffontaines: «Contacts de l'Institut Français avec l'Université de Barcelone», 15-I1945. AMAE-F, Relations Culturelles, Enseignement 1945-1947, vol. 55.
} 
cordaban el aporte decisivo que había supuesto para su área de investigación la presencia del Instituto Francés de Barcelona. Pierre Deffontaines coordinaba el «Cercle des géographes»: alrededor de las comunicaciones y de las conferencias presentadas los participantes tenían oportunidad de intercambiar puntos de vista, y con el transcurso del tiempo tuvieron oportunidad de conocer a los más destacados geógrafos franceses. Según Salvador Llobet, la presencia de Deffontaines en Barcelona coincidió con el momento crucial en que conocidos geógrafos habían tomado el camino del exilio. Afirmaba que las cualidades humanas y científicas de Pierre Deffontaines animaron a jóvenes investigadores catalanes a iniciar trabajos en geografía moderna. En fin, los estudiantes encontraban en la biblioteca del Instituto Francés libros que, en su defecto, no hubieran podido obtener.

«Ara, en aquests moments en què es troben bones biblioteques al Departament de Geografia de les Universitats i al Consell d'Investigació i altres institucions, és dificil copsar la importància que tenia l'adquisició de llibres estrangers en una biblioteca com la de l' Institut Francès, en la qual la mà del geògraf s'hi deixava sentir. En aquells anys, que ens calia adquirir personalment a cadascú tots els llibres d'interès científic, però que malauradament les mitjans econòmics de tots nosaltres no permitien, i que els llibres ja exhaurits era impossible d'obtenir, això tenia una importància extraordinària per a tots» 78 .

El cierre de la frontera no provocó una disminución de la matrícula en los centros culturales y escolares. A pesar de que las restricciones presupuestarias iniciadas en 1946 se tradujeron en un aumento en el precio de las matrículas, en grupos de alumnos sobrecargados y en la supresión de puestos docentes, el número de alumnos continuó aumentando. Los equipos directivos se veían obligados a rechazar inscripciones, al no tener los medios económicos para proceder a obras de ampliación de los edificios y para contratar más personal. Según Jacques Coiffard, las posibilidades de expansión del idioma francés eran «casi ilimitadas» en Cataluña, y tan sólo frenadas por la falta de presupuestos. Las escuelas primarias, obligadas a limitar las matrículas, podrían «dar una enseñanza en francés a 405.000 jóvenes catalanes» ${ }^{79}$. De la misma manera, las clases nocturnas organizadas por el Instituto acogían a 1100 alumnos, "es decir dos veces más que en los años más prósperos de la guerra civil» ${ }^{80}$. Los efectivos del Liceo Francés de Madrid habían sido duplicados en 10 años. A finales de 1946, Bernard Hardion estimaba en 10.000 el número de alumnos escolarizados en las escuelas y Liceos Franceses ${ }^{81}$.

78 Salvador LLOBET, «Els primers temps de Pierre Deffontaines a casa nostra», Revista de Geografía, vol. XIV, nums. 1-2 (enero-diciembre 1980), p. 14.

79 Jacques Coiffard à Jacques Truelle, 19-V-1945. AMAE-F, Relations Culturelles, Enseignement 1945-1947, vol. 51.

80 DGRC: «Les œuvres françaises en Espagne». 20-XII-1946, doc. cit.

${ }^{81}$ Bernard Hardion à la DGRC, 27-XII-1946. AMAE-F, Relations Culturelles 1945-1970, Enseignement 1945-1947, vol. 55. 
La atracción por la lengua y la cultura francesas no alcanza a explicar semejante afluencia. El éxito cosechado por los centros escolares y las manifestaciones culturales francesas, en general, no se puede separar del contexto político español. Se habían convertido en válvulas de escape a la enseñanza oficial, en medios para acceder a producciones culturales al margen del régimen, en una vía para mantener los contactos con la cultura europea contemporánea. En Cataluña tales motivaciones venían acompañadas de una reivindicación catalanista reforzada por el centralismo del régimen. Así, en 1940, el Rector de la Universidad había remitido una nota a Pierre Deffontaines en la cual prohibía el uso del catalán durante los recreos: "Resultado: para no hablar castellano, los alumnos bablan francés» ${ }^{82}$.

En una carta a Jacques Truelle, el Cónsul en Barcelona subrayaba que era de interés para Francia "proteger y reunir a los intelectuales catalanes y seguir siendo para ellos su fuente de inspiración, su modelo» ${ }^{83}$. A través de la creación de círculos artísticos y científicos ${ }^{84}$, el Instituto de Barcelona ofrecía un punto de encuentro para la élite intelectual barcelonesa. Para Bernard Hardion, Pierre Deffontaines había conseguido evitar con habilidad:

«tout en maintenant à son activité le rythme intelligent et dynamique qui est le sien depuis six ans, et la même orientation pro-catalane, de donner prise aux accusations des éléments hostiles de notre pays» 85 .

En efecto, después de proceder a una investigación, la Jefatura de Policía de Barcelona concluía que Pierre Deffontaines era un ciudadano libre de sospecha:

«...observa buena conducta moral en todos los aspectos, carece de actividades políticas de ninguna clase, profesa la religión católica...»86.

Es cierto que los responsables franceses se abstuvieron de toda actividad política, deseosos de mantener buenas relaciones con las autoridades, en un contexto bilateral tenso. No dudaron incluso en sancionar cualquier incumplimiento de esta norma. En abril de 1947, la policía descubrió el Archivo de la F.U.E ${ }^{87}$ en el Liceo Francés de Madrid, junto a material propagandístico de la organización clandestina y algunos explosivos. Bernard Hardion dirigió una carta a Alberto

82 Pierre Deffontaines: «Note pour le futur Institut Français de Barcelone», doc..cit.

83 Jacques Coiffard à Jacques Truelle: «Le problème catalan et les œuvres françaises. Rapport de Pierre Deffontaines», 23-I-1945. AMAE-F, Relations Culturelles, Enseignement 1945-1947, vol. 55.

${ }^{84}$ El Instituto Francés albergaba le Cercle Maillol, le Cercle Lumière, Carrefour (asociaciones de antiguos alumnos), Círculos literario, jurídico y de geografía, etc.

85 Bernard Hardion à la DGRC: «Les oeuvres françaises en Espagne. Bilan d'une année», 27XII-1946. AMAE-F, Relations Culturelles, Enseignement 1945-1947, vol. 51.

${ }^{86} \mathrm{~J}$. Albert Rodríguez, Gobierno Civil de la Provincia de Barcelona. Dirección General de Seguridad. Jefatura Superior de Policía, 11-VII-1949. AMAE-E, R 7273/exp. 33.

${ }^{87}$ Federación Universitaria Española. 
Martín Artajo, Ministro de Asuntos Exteriores, con objeto de rectificar algunas informaciones publicadas, según él de forma tendenciosa, en el diario Arriba. Hardion lamentaba que algunas «ovejas negras» hubieran conseguido engañar a la dirección del Liceo, y recordaba que la misma Dirección General de Seguridad había reconocido que ésta, «siempre había demostrado una perfecta lealtad»88.

El 9 de diciembre de 1947, se declaró en Barcelona una huelga de profesores franceses en solidaridad con la lucha que sus colegas llevaban desde Francia. Algunos días más tarde, la Direction d'Europe preguntaba a la DGRC acerca de las medidas que era conveniente tomar contra «el instigador de semejante movimiento que equivale en las circunstancias actuales a un verdadero sabotaje de los intereses franceses en la península» ${ }^{89}$. Considerando que había violado la ley española que prohibía la huelga, el Quai d'Orsay decidió que Pierre Vilar debía volver a Francia ${ }^{90}$. Es de notar que dicha sanción no fue motivada por presión alguna de las autoridades españolas, ni tampoco de la prensa que apenas comentó el incidente ${ }^{91}$.

La forma en que los responsables franceses gestionaron aquellos episodios demostraba una firme voluntad de no dar lugar a dudas sobre sus intenciones: ninguna provocación y respeto absoluto por las leyes de un régimen que manifestaba hacia ellos «una hostilidad apenas disimulada». La gran prudencia demostrada por los franceses correspondía a lo que Bernard Hardion llamaba «un sentido muy claro de los intereses en juego» ${ }^{92}$. En la fase más crítica de las relaciones bilaterales, el estatuto legal de los centros franceses seguía sin definirse, y se consideraban un objetivo de potenciales represalias. Paradójicamente, a pesar de que el año 1947 había brindado a las autoridades españolas dos ocasiones perfectas para llevar a cabo su recurrente amenaza de cierre, en ambos casos se mantuvieron al margen, dejando a los franceses solucionar los incidentes.

Sin embargo, más allá de la aparente neutralidad, en Barcelona la presencia cultural francesa sirvió de parapeto para la identidad catalana, y los centros franceses congregaban, a juicio de sus responsables, a "todos los que han sido amordazados 0 se muestran disconformes con el régimen»93. Los muros del Instituto Francés creaban un «ambiente» que atraía a los intelectuales que buscaban «un apoyo moral» ${ }^{94}$. A través de la programación cultural, o en las secciones de las bibliotecas, se ponían al alcance del público español obras y libros que se sustraían a la censura del régimen: en mayo de 1947, el Bulletin anunció la entra-

88 Bernard Hardion à Martín Artajo, 13-IV-1947. AMAE-E, R 3028/exp. 32.

89 Note de la Direction d'Europe à la DGRC, 13-XII-1947. AMAE-F, Relations Culturelles, Enseignement 1945-1947, vol. 52.

90 Anne DulPHY, «Enseignement français et francophonie dans les pays du nord de la Méditerranée pendant la IV ème République», Relations Internationales, num. 115 (autum 2003) p. 358.

91 Anne Dulphy, op.cit. p. 302, nota 3.

92 Bernard Hardion à la DGRC, 27-XII-1946, doc.cit.

93 Jacques Coiffard à la DGRC, 6-VIII-1946. AMAE-F, Relations Culturelles, Enseignement 1945-1947, vol. 56.

94 Jacques Coiffard à Jacques Truelle: «Le problème catalan et les œuvres françaises. Rapport de Pierre Deffontaines», doc.cit. 
da del libro de Louis Aragon titulado L'bomme communiste. Se difundió ampliamente la obra de Sartre. En español, fue posible tener acceso a los poemas de Lorca y al libro de Santiago Montserrat: Antonio Machado, poeta y filósofo. En el transcurso del año escolar 1947-1948, 8.700 libros habían sido prestados en el Instituto de Madrid y 8.500 en Barcelona ${ }^{95}$.

«... nos bibliothèques sont à peu près les seules qui puissent tenir au courant le public et maintenir ce contact avec l'extérieur qui reste indispensable à la production scientifique et à toute activité intellectuelle»96.

Tales comentarios resultaban obviamente un tanto desmedidos, pues trataban de resaltar su contribución en ese sentido. También infravaloraban el papel de otras instituciones extranjeras que desempeñaban un papel análogo, como la Casa Americana o el British Council, que competían con los centros franceses por ganar audiencia en la vida cultura y científica española. Pero todo ello no desmerece la labor que desarrollaban como espacios de apertura y encuentro intelectual libres del asfixiante entorno de la ideología franquista dominante.

En cuanto a los Institutos y las escuelas de otras localidades, si no estaba a su alcance organizar las mismas conferencias que en Madrid y Barcelona, recibían algunas exposiciones y, a través del sistema de préstamo, los lectores podían consultar los mismos libros que los lectores de las grandes ciudades. En febrero de 1946, el Instituto de Madrid y la Embajada organizaron varios actos con motivo del 50 aniversario de la invención del cine. Por este motivo se presentaron una exposición documental y proyecciones de películas, incluso algunos largometrajes fueron prestados a salas privadas:

«Ces mêmes cinés clubs ont pu projeter quelques films français, auxquels la censure aurait rigoureusement interdit l'accès en Espagne bien qu'ils constituassent des réalisations de qualité (par exemple Le Puritain) ces films ayant été fourni par l'Ambassade»97.

Hay una puntualización que resulta conveniente introducir. Si bien los centros culturales franceses brindaron espacios reducidos de libertad a un país sometido a un régimen dictatorial, es preciso matizar el retrato hecho por los propios cuadros de la misión universitaria francesa cuando se reclamaban como anti-franquistas o como «gaullistes de la première heure».

En efecto, durante la guerra civil las dos principales figuras de la red cultural francesa, Paul Guinard y sobre todo Maurice Legendre, apoyaron al bando franquista. En junio de 1939, el director del Instituto Francés de Madrid comentaba a Jean Marx, jefe del SOFE, que varios amigos suyos desempeñaban

\footnotetext{
95 Bulletin, num. 26 (mayo-junio 1948), p. 28.

96 Bulletin, num.11 (octubre 1946), p. 3.

97 Jean Hugues Conseiller au Ministre de l'Économie Nationale, 22-XI-1946, doc. cit.
} 
cargos oficiales en la España de los vencedores, entre ellos el coronel Ungría, alto responsable de la vigilancia policial.

Además, para organizar la reapertura de los centros culturales y escolares después de la guerra civil, Guinard aconsejaba nombrar únicamente a profesores «compatibles» con el régimen español y descartar a las personas conocidas por sus opiniones republicanas. Aunque «compatible» no significaba necesariamente partidario del régimen, algunos profesores apoyaban sin reparos a Franco y mantenían relaciones útiles en los círculos oficiales. Por ejemplo, en el Instituto Francés de Madrid cabe mencionar al abate Pierre Jobit o a Gabriel Laplane quien mandó incluso por escrito su adhesión al gobierno de Burgos. En 1942, el Teniente Laplane era prisionero de guerra. El Ministerio de Asuntos Exteriores español encargó a su Embajada en Berlín que realizara «las gestiones oportunas» en favor de la liberación del profesor francés, por ser un hombre que se había «mostrado siempre amigo de España y simpatizante con nuestro Movimiento Nacional»98.

Ante el gobierno de Vichy, la postura adoptada por los expatriados no se diferenció de la actitud observada por la población francesa en el territorio nacional. La mayoría de los funcionarios residentes en España comulgaban con el culto a Pétain y confiaban en el «vencedor de Verdun» para salvar al país. Además, en el caso particular de la red cultural francesa en España, circunstancias particulares reforzaron el afecto de los expatriados hacia la figura del viejo Mariscal. En primer lugar, Pétain había sido Embajador en Madrid hasta el mes de mayo de 1940. Por lo tanto había tratado directamente con los directores de los Institutos de Madrid y de Barcelona. En el caso de Pierre Deffontaines, hijo de un general muerto en el campo de batalla en la guerra de 1914, sus lazos con el Mariscal eran incluso más fuertes. Además, Deffontaines le debía su cargo de Director del Instituto Francés, ya que había sido nombrado en Barcelona gracias a la intervención de Pétain.

Cuando en la primavera de 1943, Paul Guinard y Pierre Deffontaines decidieron hacer pública su voluntad de romper con las autoridades de Vichy, escribieron personalemente al jefe del estado francés para explicarle su actitud. Cada una de las dos cartas constituye un testimonio elocuente de la firmeza de sus sentimientos de afecto hacia la persona del Mariscal, por más que se reclamen partidarios convencidos del gobierno de Argel. Anti-nazis, incondicionales de Pétain pero no de su gobierno, los sentimientos de los responsables de la red cultural y escolar son representativos de las posturas de la colonia francesa. La carta de Guinard deja entrever el dilema que pudo representar la ruptura con Vichy:

«Mais ce que nous tenons à vous dire, Monsieur le Maréchal, (je parle aussi au nom de Deffontaines qui d'ailleurs s'il le peut vous écrira directement), s'adresse moins au Chef de l'Etat qu'à l'homme: à celui qui nous a reçus en Espagne jadis et il y a quelques mois encore à Vichy, avec une bonté paternelle-celui à qui,

98 Ministerio de Asuntos Exteriores al Señor Embajador de España en Berlín, 8-I-1942. Centre des Archives Diplomatiques de Nantes (CADN), Madrid, Service Culturel 1925-1962, vol.39. 
même s'il nous traite en enfants prodigues et ne veut plus nous connaître, un lien personnel nous unit que nous en pourrons jamais rompre»99.

Por otra parte, el compromiso gaullista reivindicado a posteriori, merece, de igual modo, algunas aclaraciones. Durante los años iniciales de la guerra escaseaban los partidarios del general de Gaulle. En España, la disidencia no se organizó a partir del mensaje de Londres, sino alrededor de la figura del general Giraud. En efecto, a finales de 1942 y con el apoyo de los aliados, Giraud encabezó desde Argel un proyecto alternativo al del general de Gaulle, que pretendía reanudar el combate contra el invasor alemán, pero conservando el marco político del régimen de Vichy ${ }^{100}$.

Unos días después del desembarco aliado en Africa del Norte, las tropas alemanas invadieron la totalidad del territorio metropolitano. Para la mayoría de los franceses, con la ocupación del sur del país el gobierno de Vichy dejaba de existir. El Mariscal ya no era más que el prisionero del Reich. En tal contexto, Paul Guinard expresaba su adhesión al general Giraud:

«Or, le Maréchal, chef de l'Etat, et ses ministres sont prisonniers de fait, et il n'y a plus de véritable gouvernement dans la France continentale. En revanche, trois départements échappent à l'occupation allemande; un général français y a pris la direction des affaires publiques et une armée française se forme sous son commandement . Nous jugeons que tous les Français qui le peuvent doivent participer à la guerre qui reprend pour la libération du territoire national»101.

En mayo de 1943, Guinard y Deffontaines, junto a la casi totalidad de los profesores de los Institutos y Liceos de Madrid y de Barcelona, se pusieron a disposición del Comité Francés de Libération Nationale (CFLN), encabezado en un primer momento por los dos generales, hasta que de Gaulle se hizo con el mando dejando a Giraud en un segundo plano. A partir de la evolución de los acontecimientos, del encuentro con franceses comprometidos con la disidencia, de la ayuda prestada a compatriotas «évadés de France» que huían del régimen de Vichy buscando llegar a Argel, los responsables de la red cultural francesa fueron asumiendo posturas menos conservadoras.

En la postguerra, los Institutos franceses de Madrid y Barcelona se convirtieron en canales difusores de la gesta del general de Gaulle y la Resistencia. El contexto español ofrecía precisamente un terreno adecuado para reavivar el mesianismo francés, en tanto que las alusiones al papel de la Resistencia francesa cobraban, en la España franquista, un significado especial.

99 Paul Guinard au Maréchal Pétain, le 20 mai 1943. Archivo de la Biblioteca de CatalunyaBarcelona (ABC-B), Fondo Deffontaines, Caja 6.

100 Robert BELOT: Aux frontières de la liberté. Vichy-Madrid-Alger-Londres. S'évader sous l'Occupation. Paris Fayard, 1998, pp.141-201.

${ }^{101}$ Note de Paul Guinard, le 13 novembre 1942, ABC-B, Fondo Deffontaines, Caja 6. 
En los informes dirigidos al Quai d'Orsay, la repetición de unos cuantos términos indicaba que se concebía la presencia cultural como una causa noble que debía defenderse en un contexto amenazador. Se hablaba de familias españolas «simpatizantes», de un público «orientado hacia» Francia o de profesores desinteresados cuya única preocupación era la defensa de «posiciones francesas». El Instituto de Barcelona tenía la misión de atraer a jóvenes artistas «a nuestra esfera de influencia». Francia tenía que responder "a ese llamamiento» que le dirigía una oposición española claramente asimilada a la Resistencia francesa. A propósito de ediciones clandestinas publicadas en Cataluña, Jacques Coiffard afirmaba:

«He visto yo mismo algunas muestras con una presentación artística y lujosa. Estamos en presencia de un fenómeno análogo al de nuestra poesía de la resistencia en Francia»102.

El prestigio de la Resistencia francesa, la campaña de restauración de la imagen de marca de «Patria de los Derechos Humanos» concedían un indiscutible valor añadido a los centros culturales y escolares franceses en la España franquista. A finales de 1946, Bernard Hardion explicaba al Ministerio de Asuntos Exteriores que, a pesar de las dificultades materiales y políticas, el trabajo efectuado bajo el impulso de Paul Guinard y de Pierre Deffontaines había permitido consolidar posiciones morales que «contribuent si grandement au prestige de notre pays, au rayonnement de sa pensée et de son idéal politique dans toutes les classes de la péninsule»103.

$$
* \quad * \quad * \quad * \quad *
$$

En la postguerra mundial un sector de la opinión pública y de la clase política francesas consideraron la ruptura con el régimen de Franco como la vía que Francia debía seguir para reanudar su vocación mesiánica, reencontrándose así con los valores básicos de su unidad nacional y de su proyección exterior. Desde España, los responsables de la red cultural ofrecieron otra lectura de los medios a utilizar en el cumplimiento de la «misión de Francia». Si desde París el odio contra Franco acabó creando una amalgama entre el dictador, la población y el propio país, los franceses residentes en España no cayeron en tal simplificación.

En un informe redactado en 1945, Paul Guinard comentaba que habían establecido contactos en todos los medios, postura que sirvió para formarse una visión más precisa de la realidad circundante. Efectivamente, las posturas de los responsables franceses evolucionaron, diversificaron sus contactos en la sociedad española. Los Institutos de Madrid y de Barcelona abrieron sus puertas a perso-

102 Jacques Coiffard à Jacques Truelle, 23-I-1945, doc.cit.

103 Bernard Hardion au MAE, 27-XII-1946, doc. cit. 
nalidades como Julián Marías, Miguel Catalán o Joan Miró. Además, España era para ellos un campo de estudios al cual dedicaron gran parte de sus vidas. Los dos directores de los Institutos franceses publicaron numerosos trabajos sobre el arte español durante el Siglo de Oro (Paul Guinard), y sobre la geografía de Cataluña (Pierre Deffontaines). El contexto español de la postguerra les brindó la posibilidad de desarrollar una carrera que seguramente no hubieran podido vivir en Francia, y acabaron considerando a España como su segunda patria ${ }^{104}$

Su conocimiento sobre el terreno de la situación española les llevó a plantear una estrategia de actuación que privilegiaba la acción a largo plazo y descartaba las soluciones coyunturales. A partir de 1945, los responsables franceses destacados en España intentaron convencer a París de la necesidad de abandonar la acción política inmediata, de optar por una acción cultural discreta y adaptada al público español. El papel que Francia estaba en condiciones de representar para favorecer el restablecimiento de la democracia en España consistiría en contribuir a la formación de la futura élite, amparando entretanto a la resistencia intelectual interior y proporcionándole material capaz de superar el restrictivo y limitado panorama cultural franquista ${ }^{105}$. Los instrumentos serían los libros y películas, las becas para estudiar en Francia, los ciclos de conferencias y trabajos de investigación orientados por equipos bilaterales, en suma, las ideas y el ejemplo a emular:

«A condition d'être active, mais respectueuse du patrimoine ibérique, à condition de se montrer vivement désireuse d'un échange intellectuel, voire d'une émulation entre peuples ayant la même origine, il n'est pas de raison que la France ne continue d'être le pays vers lequel les esprits se tournent volontiers chaque fois qu'ils s'efforcent de découvrir par delà leurs frontières un motif d'espoir, un exemple à suivre ou tout simplement une mode à imiter»106.

Ese reencuentro con la confianza en el prestigio de Francia en el exterior, pero también con el sentido de la misión a realizar en España, constituirían puntos de apoyo esenciales de la acción cultural francesa. A partir de 1946, el Estado francés aplicó drásticos recortes presupuestarios a su presencia en el exterior, pero dejó en prenda a los funcionarios que la representaban más allá de sus fronteras y al público español «une certaine idée de la France» ${ }^{107}$.

104 Paul Guinard à Bernard Hardion, 13-IV-1947. AMAE-F, Relations Culturelles, Enseignement 1945-1947, vol. 52.

105 «...si nos livres, nos écrivains, nos savants et professeurs pouvaient, après un silence de cinq ans prouver, par leur présence dans la péninsule ibérique, la vitalité de notre culture, en dehors de toute propagande politique les sentiments et les principes démocratiques s'imposeraient plus facilement Note du MAE (Paris) «Les relations culturelles avec l'Espagne et le Portugal». AMAE-F, 10-X-1946, doc. cit.

106 Ibidem.

107 «Toute ma vie je me suis fait une certaine idée de la France». Charles de GaUlle, Mémoires de Guerre. L'Apppel 1940-1942, T.1, Paris, 1954, p. 5. 